\title{
The Student's Visual Thinking Profile in Solving Mathematics Problems
}

\author{
Ummu Sholihah ${ }^{1}$, Beni Asyhar ${ }^{2}$ \\ Department of Mathematics Education \\ Institut Agama Islam Negeri (IAIN) Tulungagung \\ Tulungagung, Indonesia \\ ${ }^{1}$ u.sholihah@yahoo.com \\ 2asyhar_beni@yahoo.com
}

\begin{abstract}
The ability to solve problems is the heart of mathematics. Students of mathematics have few difficulties in understanding the formal definition of integrals and it results in their difficulties also in solving the problems associated with the integral concept. Generally the formal definition is memorized, thus having no mental imagery of the formal definition of integrals. To get the mental imagery, students need to think visually. This study aims to obtain a visual thinking profile of mathematics students in solving integral problems. This research using descriptive-explorative method with qualitative approach. Research subject taken from the Department of Mathematics Education FTIK IAIN Tulungagung. Data research was collected using a task-based interview method with the format semistructured. The research data is validated by using time triangulation. Data research was analyzed with categorization, reduction, exposure, interpretation, and drawing conclusion. The results of the study show the visual thinking profile of mathematics students in integral problem solving, that is: To solve the integral problem by using visualization, students recognize, imagine, show and conclude. To recognize, students show what is known and describes what can be described. For Image, students download settlement plan and make public pictures. To show, students make special integral formulas, using images. To show, students illustrate to make it easier to use the correct approach. For concluded, students rechecking and conclusions.
\end{abstract}

Keywords—Visual Thinking; Problem Solving; Integral

\section{INTRODUCTION}

In a learning activity mathematics consists mostly of symbol manipulation. Shapiro says that many activities pertain to mathematics that comprise from the manipulation of symbols according to certain rules [11]. This is more visible in the flow formalism. Shapiro explains that adherents of formalism view that mathematics is about symbols and numbers [11]. Tall says that research clever students seem to prefer use symbols and lack visualization [18]. Illustration is the result of visualization of a writing with drawing, painting, photography, or other art techniques that emphasize the relationship of the subject with the text in question rather than the form. The definition explains that the illustrations are used to decorate or explain the text in a particular object, to help one translate the meaning of the illustration given, especially in understanding the abstract mathematical concepts. The use of visual illustrations in mathematics learning has been the subject of much research . Arcavi defines that "visualization is the capability, process and product of creation, interpretation, use and reflection of images, images and diagrams present in our minds, on paper or by technological devices, for the purpose of describing and communicating information, thinking and developing ideas that were previously unknown and to improve understanding [2].

There are several research results showing the importance of visual thinking. Nemirovsky \& Noblemany says "researchers emphasize the importance of visualization and visual reasoning for learning mathematics"[6]. Hartono recounts that Plato analyzes memories as a wax block and perception forms a mold on it. Aristotle explains that the print is in the form of image and language is its representation [3]. Tall explains that to prove, there must be a picture of the proof or truth of the theorem obtained from visualization [16]. Suharnan explains that visualization can improve memory performance and creative thinking ability [13]. Nemirovsky \& Noblemany wrote that the researchers suggested the importance of visual reasoning for mathematical learning [6].

Suharnan says that in order for a correct problem to be solved, one must be concerned first understand and recognize the main picture issues clearly. Understand important because it underlies a higher cognitive process [13]. Santrock provides six categories of Bloom's cognitive dimensional process: remembering, understanding, apply, analyze, evaluate, and create [9]. According Suparman and Anderson \& Krathwohl the problem of understanding many found at the level universities and levels below because it is the basis for studying and master the levels of taxonomy above it [15][1].

Several factors influence the individual's visual thinking. Sternberg explains that not everyone is equally fluent in creating and manipulating mental imagery because it is influenced by individual factors, definitions or tasks, and experience or interaction [12]. Jensen explains that learning that meaningful demanding students to process in formation in their own way in problem solving [4]. 
the calculus they develop an integral concept associated with a derivative. So the integral can be defined as anti derived. The modern definition of the integral put forward by Riemann with his first idea is the number of Riemanns. This idea raises the link between the integral and the area. In general, the integral necessarily denotes the boundary of the area covered between the curves $y=f(x)$ and the $x$-axes in the interval $[a, b]$. Sizewide section section located at the top of the $x$-axis is given a positive sign, while the area-wide section section located at the bottom of the $x$-axis is given a negative sign.

Numerous studies have shown that the representation used by students in solving integral problems is related to the meaning of the noise with the concept of integral. Graphical representation of integrals is usually used in calculations involving areas under the curve, whereas numerical representation is used for the cumulative summation problem of Riemann. Thompson an integral settlement using common integration techniques indicates the need for symbolic representation [19].

The focus of this research is about student's visual thinking profile in solving math problems . Thus, provide an overview of a series of activity or student activities in solving mathematical problems, especially the problem of integral of course by using visualization and provide an overview of a series of activities or visual thinking activities of students in solving math problems . The series of activities or activities of the results of research can be a reference in solving the integral problem by using visualization, namely: recognize, imagine, show, and conclude.

\section{Methodology}

The focus of this research is more on the process than the results so that it is qualitative. Results research is presented in descriptive form with words or sentences according to the data empirical. Empirical data obtained are natural and through deep exploration. Therefore, descriptive-explorative research is used with qualitative approach. Subject selection is done in Department of Mathematics Education FTIK IAIN Tulungagung of the academic year $2017 / 2018$ as the first place researchers find the problem. To achieve subject equality and reduce the differences due to other uncontrollable variables, subjects are expected in the same class with criteria: 1) have received calculus material, 2) have GPA above $2.75,3$ ) calculus value and introduction to basic mathematics minimal $\mathrm{B}, 4$ ) communicative and willing to be the subject of research. To obtain saturated and deep data can be required long and exhausting interview. The first instrument in this study was the researcher himself. Here are 5 integral problems of course (Fig. 1.). representations and develop a deeper understanding of concepts. Integral and derivative are important concepts in mathematics. Integral and derivative are the two main operations in the calculus. The integral principles were formulated by Isaac Newton and Gottfried Leibniz in the 17 th century by making use of the close relationship that exists between anti-derivatives and integral of course, a relationship that enables us to easily calculate the true value of many integrals of course without the need to use Riemann sums. This relationship is called the fundamental theorem of calculus. Through the basic theorem of 
1. If $\int_{2}^{4} f(t) d t=9,7$, use two strategies algebra and geometry to evaluate the value of $\int_{3}^{5} f(t-1) d t$.

2. Use algebra and geometry to calculate $\int_{-5}^{5}|x+3| d x$.

3. Determine the area of shaded area in the following figure by using the integral.

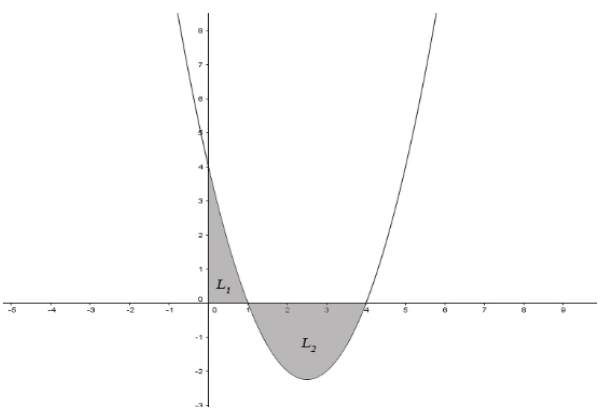

4. If $\int_{2}^{6} f(x) d x=11$. Calculate the value of $\int_{2}^{6}(f(x)+3) d x$.

5. Draw the region $R$ bounded by $y=x+6, y=x^{3}$ and $2 y+x=$ 0 . Then calculate the area $R$. ( hint: for $R$ to be 2 )

Fig. 1. Task Sheet

These problems enabled the students' performance regarding the visual thinking to be analysed. The results of the questionnaire necessitated further investigation into the visual thinking of the students. Each interview lasted about 15-30 minutes and was video- and audio-taped. In order to prepare the script for the interview, the author analysed the written answers focused on to how the students seemed to use and coordinate the different mathematical representations needed.

\section{RESULTS AND DISCUSSION}

Profile of visual thinking of mathematics students gained based on the data or information provided by the subject in solving the integral problem. Not all information processing activities in solving integral problems are revealed by the subject that researchers in qualitative research are required to be responsive, adaptive, holistic, and sad in unspeakable contexts.

A series of activity or subject activities in solving integral problems. Subject solves the integral problem by recognizing, imagine and conclude.

\section{A. Activity Recognize}

Here is a snapshot of an interview that describes a series of activities or subject activities solve integral problems

In question number 1, First I read the problem, just write down the known like this

$$
\text { musal } \int_{2}^{4} f(t) d t=9,7
$$

Then I set the upper border with $p$ and the lower border with q like this

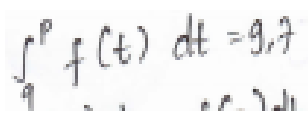

After that, I describe the integral form of the definable definition (write down the translation)

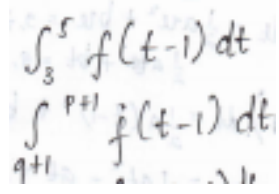

So obtained the following results

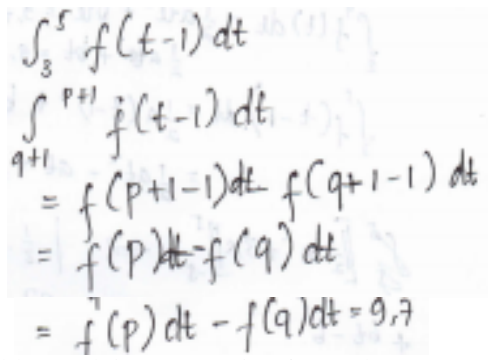

Fig. 2. Siti's Problem Solving Processing for Task 1

To recognize, the subject makes a general formula, summarizes the definitions, and describes what can be described. The task of understanding stimulates the activity of recognizing according to Schunk's explanation that information processing starts from the stimulus input [10]. To recognize need to read according to Schunk's explanation that the reader looks for important material and notices it. Important material is obtained from scan according to Sternberg's opinion that people pull information by doing scanning [12]. Attention is needed to recognize according to Suharnan's explanation that attention is focused on a stimulus [13][20]. The information from the definition is transformed into memory as per Santrock's explanation that thinking involves the activity of transforming information in memory [9]. Identifying activities is the first activity to understand, accordingly explanation Roam that recognize meaning men and choose the information to be examined in detail by the patterns known [7]. Activity recognize is very important in solving integral problems. It is also in the opinion of Rose \& Nich oll that we need to dig as much information as possible to understand the message correctly [8].

\section{B. Activities Imagine}

Here is a snapshot of an interview that describes a series of activities or activities imagine resolving integral issues. This is seen in answer no 2

Then, I made a general chart (drawing graph)

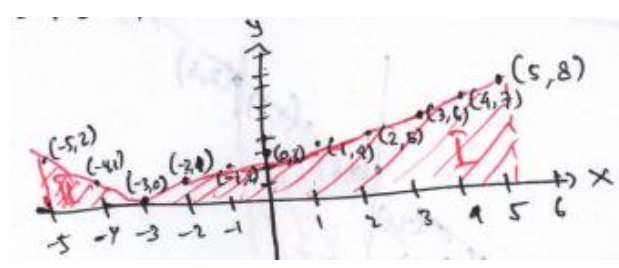

Figure 3. Siti's Graphical Presentation for Task 2 
This I get by making like this first

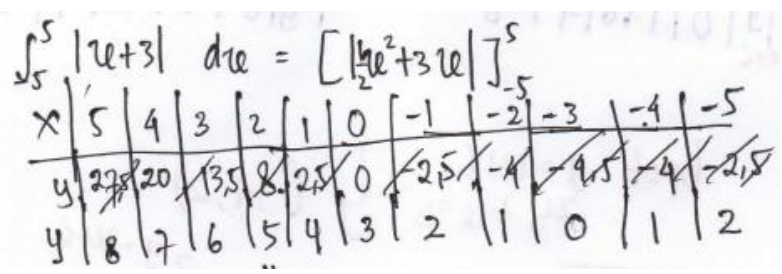

so it can be seen broadly its area ie

$$
\begin{aligned}
& I=\frac{1}{7} \cdot 8 \cdot 8=32 \\
& I=\frac{1}{7} \cdot 2 \cdot 2=2
\end{aligned}
$$

So the total area of 34

To imagine, the subject makes a general idea. A series of activities or visual thinking activities to illustrate the general picture namely: bring up mental imagery by remembering or calling mental imagery of integral concepts and creating other mental imagery still in the form of graphs, then cultivate the mental imagery by collecting all mental imagery and then choosing or focusing attention to a mental imagery, and then use or represent it as a general picture by describing .

Being an input activity imagine is the visual input of the result of recognizing the appropriate explanation Schunk that information processing starts from the stimulus input [10]. Scanning information occurs to obtain an integral visual input according to opinion Sternberg that people pull information from active memory with perform scans of items in sequence [12]. Scanning repetition information to get the right visual input can happen to the activity imagine as per Santrock's explanation that the suggestion is repeats the information consciously to increase the amount of information resident in memory [9].

Activities utilizing mental imagery are necessary to imagine Schunk explanation that information processing is directed or controlled by a particular purpose [10]. Activity imagines very important in the opinion of Roam that imagine is the activity of processing visual inputs to get a decision [7].

\section{Events Show}

Here is a snapshot of an interview that describes a series of activities subject activities show an integral completion picture .

From the picture is known

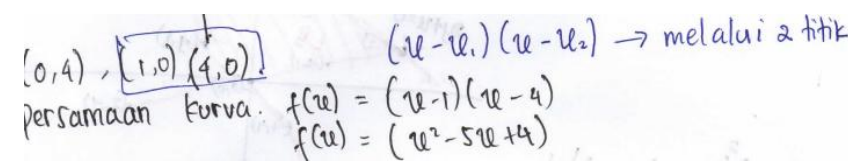

Because through 2 points,

$$
\begin{aligned}
\text { Luas kurya } & \int_{0}^{1} f(u) d u \\
& =\int_{0}^{9} u^{2}-5 u+4 d u
\end{aligned}
$$

After that, I finish like this by using integral, because from the graph there is that above the $x$ axis and below the $x$ axis, then

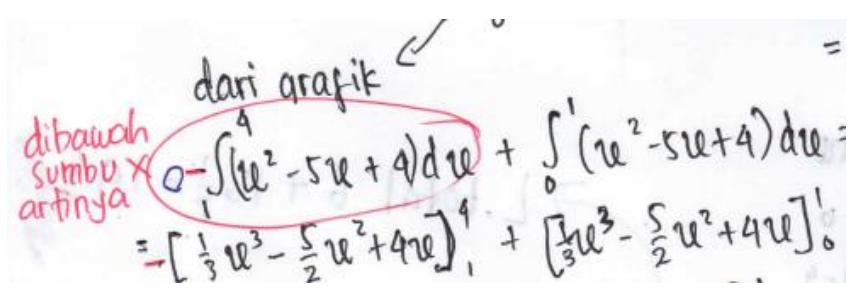

In a series of activities or visual thinking activities to solve integral problems namely: bring up mental imagery by summoning mental imagery overview and create other mental imagery, cultivate mental imagery which arises by collecting the mental imagery and completing it The mental imagery by adding integral formula, then choose The mental imagery with memfok uskan attention to one of the mental imagery, then take advantage of it or use a pad that mental imagery selected to complete .

To get a visual input needs attention in the opinion of Suharnan and Woolfolk that attention is concentration of mind or focus against an object or a stimulus [13][20]. Scanning is done to obtain information which draws attention to Sternberg's (2008: 234) opinion that people are attractive information from active memory by scanning. Transformation of information occurs in the opinion of Anderson \& Krathwohl that one process cognitive in understanding is transforming information from one form to another [1]. A series of activities or visual thinking activities to determine the value of: bring up mental imagery by watching or calling for imagery integral mental plot existing and create mental imagery advanced integral plot, cultivate mental imagery by collecting mental imagery plots the integral that arises, and utilizes or uses the mental imagery information to determine the value or invoke the mental imagery of the existing image/graph and create another mental line deviation, then process or determine the imagery.

\section{Activities Conclude}

The following snippets of interview results that describe a series of activity or subject activities conclude broad integral results .

Means the area shaded in the problem no. 3 is

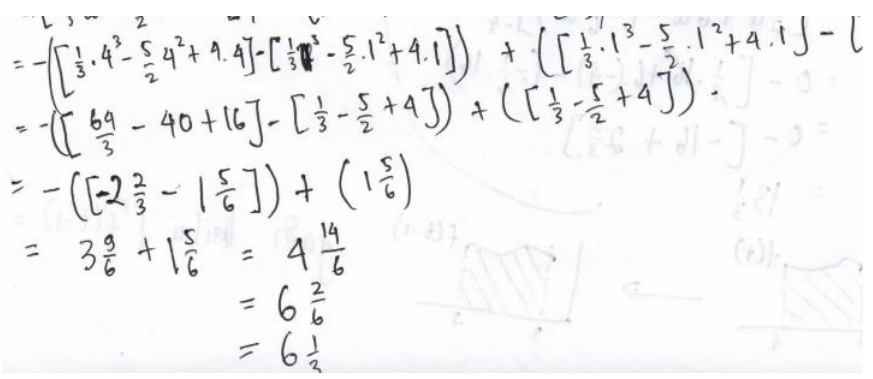

Fig. 4. Siti's Problem Solving Process for Task 3 
concluding, the subject checked off and make conclusions. Input this activity is the result of scanning of the information the results of the activities-activities in accordance with the explanation previously Sternberg that people draw information by performing a scan [12]. Conclusion concepts occur as a result of information processing in concluding activities according to Suharnan's opinion that concept formation is the use of certain rules to categorize objects that have similarities in their structure or function [13]. The repetition of information processing can occur in conclusions, in the opinion of Santrock that repetition is a conscious repetition of information to increase the amount of information resident in memory [9]. The representation of each individual activity on the concluding activity may differ according to Rose \& Nicholl's opinion that the information rossaging in mind is complex [8]. The concluding activities are important to represent the results of all activities in understanding by Anderson \& Krathwohl that concluding means abstracting a concept or principle by looking at its characteristics and drawing connections between them [1].

\section{CONCLUSIONS AND RECOMMENDATIONS}

Based on activities carried out, the students do some activities to resolve a problem integral to using visualization, that is: know imagine, show and conclude. Acknowledgment activities are done by summarizing the definition and describing what can be described. Imagining activities is done by creating a general overview. The show's activity is done by creating an integral formula and creating a graph. The activity shows is done by determining the boundary of the integral and depicting the graph curve below and above the $x$-axis . Activity concludes is done by matching and make conclusions. Based on the results of research showing that each subject has different visual thinking skills, so further research is needed on the grouping of students' visual thinking skills.

\section{REFERENCES}

[1] Anderson \& Krathwohl. The Foundation Framework for Teachers , Teaching, and Lessons Assessment. 2007.

[2] Arcavi, A. The Role of Visual Representations in the Learning of Mathematics. Educational Studies in Mathematics, 52,215-242. 2003

[3] Hartono. Mental Imagery: a review of terms of philosophy, Cognitive Sciences and Neurological. Surabaya: UNESA University Press. 2010.

[4] Jensen. Brain-Based Learning: The New Science of Teaching \& Training (Brain-Based Learning: A New Way of Teaching and Training). Revised Edition. Translation Narulita Yusron. Yogyakarta. Student Library.2008.

[5] Krulik, S \& Rudnick, JA, The New Source Bookfor Teaching Reasoning and Problem Solving in Elementary School . Boston: Temple University. 1995.

[6] Nemirovsky \& Noblemany. On Mathematical Visualization and the Place Where we Live. Educational Studies in Mathematics 33: 99131. Kluwer Academic Publishers, Printed in The Netherlands.1997.
[7] Roam. The Magic of Picture. Translated from The Back of Napkin. South Jakarta: Ufuk Press, PT. Ufuk Publishing House. 2011.

[8] Rose \& Nicholl. (2006). Accelerated Learning for the 21 th Century. Translator: Dedy A himsa. Bandung. Nuansa Publisher

[9] Santrock. Educational Psychology. Edition 3. Book 1. Jakarta : Salemba. 2009.

[10] Schunk. Learning Theories an Edycational Perspective. Learning Theories. 2012.

[11] Shapiro. Thingking about Mathematics: the philosophy of mathematics. New York: Oxford University Press. 2000.

[12] Sternberg. Cognitive Psychology. Title Original: Cognitive Psychology. Penerjemah: Yudi. 2008.

[13] Suharnan. Cognitive Psychology. Surabaya: Srikandi. 2005.

[14] Suherman, E. Strategy of Contemporary Mathematics Learning, Department of Mathematics Education FMIPA UPI-Bandung. 2001.

[15] Suparman. Guide of Lecturers \& Innovators: Modern Instructional Design Education. Jakarta: Erland. 2012.

[16] Tall. Intuition and Rigour: The Role of Visualization in The Calculus. Visualization in Mathematics. Notes No. 19, 105-119. 1991.

[17] Tall. Visual Organizers for Formal mathematics. Exploiting Mental Imagery with Computers in Mathematics Education. Springer-Verlag, Berlin, pp.52-70. 1995.

[18] Tall. "A Theory of Mathematical Growth through Embodiment, Symbolism and Proof ". Written for the International Colloquium on Mathematical Learning from Early Childhood to Adulthood, organized by the Center de Recherche sur l'Enseignement des Mathématiques, Nivelles, Belgium, 5-7 July 2005

[19] Thompson, P.W. Images of rate and operational understanding of the fundamental theorem of calculus. Educ. Studies in Mathematics, 26, 2-3, 229-274. 1994

[20] Woolfolk. Educational Psychology: Active Learning Edition. The tenth edition second. Yogyakarta: Student Literature. 2009. 